\title{
Parental Involvemet in the Education of African Learners with Intellectual Disabilities
}

\author{
Senosi Swanki Stephinah \\ Department of Early Childhood Education, University of South Africa \\ senosss@unisa.ac.za
}

\section{Doi:10.5901/mjss.2014.v5n20p1629}

\section{Abstract}

Amongst the many disadvantaged groups in the world, an important minority are children with intellectual disabilities. Relative to their counterparts without intellectual disabilities, children with intellectual disabilities face a wide spectrum of challenges, including learning difficulties, social segregation and negative stereotyping. This study sought to determine the effects of parental involvement in the education of children with learning disabilities. The study is both quantitative and qualitative approach. Purposive sampling was used in choosing the sample. The key informants were teachers in five different special schools, (3 in Gauteng Province and 2 in the Northwest Province). For data collection, a designed questionnaire with semistructured interview was used. The study found that there is a lack of important facilities; teachers were not trained to teach in special schools; male teachers were fewer than female teachers; learners with severe, moderate and mild disabilities were accommodated in one class and not much parent involvement in some schools, especially in rural areas. Children with intellectual disabilities find it difficult to perform various functions such as communicating and socialising with others, and in many situations, even looking after themselves.

Keywords: parental involvement, intellectual disability, learning difficulties, inclusion and special needs.

\section{Introduction}

Parental involvement is a combination of commitment and active participation on the part of the parent to the school and to the student. According to Dixon (1992), parental involvement, in almost any form, produces measurable gains in student achievement. Vandergrift and Greene (1992) add that there are levels that make up the concept of parental involvement, namely, (a) a level of commitment to parental support such as encouraging the student, being sympathetic, reassuring and understanding, (b) a level of parental activity and participation such as doing something that is observable.

'Schools must understand that lack of involvement by parents does not necessarily mean they are neglecting their responsibilities. They simply may not have the time, resources, or know -how to help out' (Wanat 1992). Parents often do not feel welcomed at school. They feel that what they may have to offer is unimportant and unappreciated. Also, parents may not believe that they have any knowledge that the school is interested in knowing. This is especially true when the parent may not have a great deal of education (Dixon 1992, Vandergrift \& Greene 1992). It is also possible that the parent does not have a great deal of interest in the school or his/her child's education. The parent may not feel that education is important (Vandergrift \& Greene 1992).

The South African Government initiated an inclusive education that was aimed at bridging the gap between mainstream schools and schools for the disabled which started in the early 2000/2001 within the mainstream schools. The Education White Paper 6 was therefore developed in order to address the imbalances of the past within the education system. It was aimed at addressing the special needs education and to build an inclusive education and training system (White Paper 6, 2001). The main aim was to ensure that children with disabilities enjoy the same benefits as children from mainstream schools.

As inclusive education continues to gain strength, it is important to understand how educators perceive the academic outcomes of students with diverse needs and abilities (Hemmings \& Woodcock, 2011). According to Clark \& Artiles (2000), students with learning disabilities (SLD) form the largest group of students with diverse needs and abilities in inclusive classroom. Specific learning disability is defined as a neurological disorder that is manifested by "significant difficulties in acquisition and use of listening, speaking, reading, writing, reasoning or mathematical skills...intrinsic to the individual, presumed to be due to central nervous system dysfunction, and may occur the life span" (NJCD, 1998).

A significant influence on students' classroom performance is teacher attitudes, (Forlin, Loreman, Sharma \& Earle, 2007, Winter, 2006). For example, research has shown that negative attitudes can lead to low expectations of a person 
(Campbell, Gilmore \& Cuskelly, 2003; Palmer, 2006). On the other hand, positive attitudes can lead to higher expectations of a person (Angelides, 2008). According to Westwood (1995), negative attitudes and low expectations by teachers can result in reduced opportunities for students to learn which may impair students' self-beliefs causing them to reduce their expectations and leading to a deficit cycle. However, positive attitudes can enhance opportunities for students to learn, which may improve their performances, self-expectations and self-esteem (Palmer, 2006; Woolfson, Grant \& Campbell, 2007). Therefore in order for inclusion to be successful (particularly for those with SLD), it is critical that teachers have positive attitudes towards students (Angelides, 2008; Winter, 2006).

An intellectual disability (ID), formerly referred to as 'mental retardation', is not a disease. It is characterised by significant limitations both in intellectual functioning and in adaptive behaviour that originates before age '18' (Schalock, Luckasson, and Shogren 2007). It ranges from mild to severe and can be measured through the use of IQ test (Pawlyn \& Carbaby, 2009). South African Federation for Mental Health (2004) states that intellectual disability is a mental condition that affects people's overall functioning which affects and limits people's conceptual, social and practical skills. Nobody can catch intellectual disability from anyone. Intellectual disability is not a type of mental illness (The Arc, 2009). There is no cure for intellectual disabilities. However, most children with an intellectual disability can learn to do many things, for example, need help with adaptive skills needed to live, work and play in the community. It just takes them more time than other children.

Learning disability (LD) is a dynamic, multifaceted, and ever-changing area of special education. In the past, people used to think of individuals with disabilities as 'misfits', and later, they were thought of as the 'handicapped'. They were regarded as individuals to be pitied, feared or ignored. They were portrayed as helpless victims, repulsive adversaries, heroic individuals overcoming tragedy, and charity cases who depended on others for their well being and care. According to Nakken \& Vlaskamp (2002), Petry \& Maes (2007), because of their complex needs caused by a combination of profound intellectual and serious motor and/or sensory disabilities, they are almost totally dependent on other people to attain an optimal life quality and well-being. Now of late, the case is made that they are 'people' first and happen to have a disability. The contention is, if they are viewed as people first and provided proper instructional interventions, they will learn.

Children with intellectual disabilities experience problems with basic activities, including eating, dressing, talking and walking. They are extremely vulnerable to depression, poor self-image and a lack of self-confidence. The pace at which they learn and grasp things is much slower than that of children without intellectual disabilities, hence the researcher found it necessary that parents of these children be committed in their education and help with ideas or strategies that would help alleviate the problem, rather than leaving everything in the hands of teachers. Green (1996) argues that early intervention with children with intellectual disabilities can produce large, comprehensive and meaningful improvements in many important domains within the learner.

\section{Problem Statement and Rationale for the Study}

Although a wide range of research has been conducted on children with intellectual disabilities, the researcher has noted that not much has been done on how much role do South African parents play in the education of their children, especially in black communities, hence the research for this paper was: Parental involvement in the education of African learners with intellectual disabilities.

Loebenstein (2005) conducted research study on the support for learners with intellectual disabilities in the transition to secondary schools. In the same breath, Adams, (2008), conducted research study on poverty and intellectual disabilities focusing on the relationship between poverty and intellectual disabilities, exclusion, poverty, resources, illhealth and policies. However, these research studies have not emphasised the role parents should play and the challenges encountered by teachers as well as parents on a daily contact with these children.

Teachers working with children with intellectual disabilities play a significant role in the lives of these children through education. Both teachers and parents have the educational mandate to empower children with intellectual disabilities through education. In South Africa, the empowerment of children with intellectual disabilities is still a national problem. The majority of the families in black communities live in poverty. This study focused on five schools, e.g., in Makapanstad, Atteridgeville, Soshanguve, Mamelodi and Bronkhorstspruit. It was significant that teachers also be made part of the research study as they work with special needs children on daily basis and they had significant input in this research study. 


\section{Research Methodology}

In order for empirical research to be a feasible and legitimate enterprise, the researcher conducted a thorough needs assessment. The key to this strategy was the active participation of teachers as well as parents. The techniques used in this study were interviews and questionnaires. According to Luftig (1989), data collected by an interview schedule are rich and spontaneous and a good interview lay open thoughts feelings, knowledge and experience not only to the interviewer, but also to the interviewee. An interview is important for the teacher to establish a rapport with the parent and to set him at ease.

The questionnaire used in this study for parents was divided into two sections. Section A contained biographical information and section B explored the feelings and attitudes of the parents of learners with intellectual disabilities. In the case of teachers, the questionnaire was divided into three sections. Section A required biographical data, section B focused on general data whilst section $\mathrm{C}$ focused on the availability of financial assistance in special schools for learners with intellectual disabilities.

Appointments were made with the respondents. Before the formal interview could begin, the interviewer introduced herself and engaged in a few minutes of small talk with the respondents to establish rapport. The purpose of the study was briefly explained in such a way as to make the respondents understand that the research was significant and important.

Research questions were as follows:

\section{For Teachers: Section A}

- How old are you?

- Are you a male or female teacher?

- Indicate your home language

- Indicate your highest qualification

- Indicate your number of years of experience

Section B

- Motivate your reason for teaching learners with intellectual disabilities

- Did your training provide you with the necessary educational skills for teaching these children?

- If yes, specify the skills

- How many learners with intellectual disabilities do you have in your class?

- What strategies do you think to employ in teaching these children?

- Do you encounter any problem in teaching them?

- If yes, specify the kind of problem you encounter (e.g. syllabus, teaching aids, practical subjects such as painting, art, woodwork, music, etc.).

- Do you try to improve your teaching skills?

- If yes, do you undergo upgrading courses, workshops, seminars, etc.?

- Do the parents of these children support you?

- If yes, what kind of support do you get from them?

\section{Section C}

- Does the Government subsidise the school?

- If yes, indicate how

- Do you try to raise additional finances/funds?

For Parents: Section A

- Indicate your gender

- Indicate your marital status

- Indicate your home language

- Indicate your highest qualifications

- Indicate your occupation

- Indicate your age

\section{Section B}

- How did you discover that your child is disabled?

- How was your feeling about it?

- Do you leave the responsibility of the education of your child in the hands of teachers? 
- If yes, be as specific as possible

- If not, how do you help the teachers?

- Where did you get information that there are special schools for the education of your child?

- Do you get any support from family members, community, welfare church, etc.?

- How is your child affected, e.g. mildly, moderately or severely?

- Knowing that your child is affected, what kind of help do you offer to the teachers?

- Are you happy with the situation regarding the education of your child?

- If yes, state reasons

- If not, what do you want to see changed in the education of your child?

- How do you see the future of your child?

\section{Data Collection}

A common questionnaire for both parents and teachers was compiled in English, as English is regarded as a 'lingua franca' in South Africa. The same questionnaire was retranslated into Setswana to accommodate those parents with limited education. Teachers were requested to help the parents. However, most parents had at least basic literacy levels and were able to complete the questionnaire in time. Instructions were simple and all questions could be answered in a very short time. The researcher also opted for interviews because they can be useful in ascertaining attitudes, beliefs and experiences of the participants. According to Schumacher and Macmillan (1997), interviews are conducted with individuals or small groups to capture participants' perspectives of their world and how they make sense of important events.

\section{Data Analysis}

The data obtained from in-depth interviews were analysed by means of procedures typical of both qualitative and quantitative research. All teachers of the selected schools took part in the interviews. The schools were helpful in permitting all teachers to participate in the research study and they were all willing to do so. The researcher made personal contact with the prospective participants and invited them to take part in the research study.

The research tool was first pilot tested with two teachers and two parents to ensure the relevance and easy understanding so as to give clear answers. All the focus groups were subjected to the same set of questions. Where there were very brief and unclear answers, probing questions were asked as a follow-up. Probing was also used to explore new themes and issues that were not initially considered (Gray, 2004, Henning, Van Rensburg \& Smit, 2004). The four participants who first participated to pilot test the research tool were not included in the research study.

Tables were used to give a clear overall picture. Data obtained from questionnaires were analysed using simple quantitative procedures. The focus was on the number of responses per item in a questionnaire.

The questions were open-ended to encourage discussion on the topic. The most advantageous thing about this data collection method was that the researcher could probe more and observe the research participants' non-verbal behaviour during the interviews. However, the disadvantage was that the researcher noticed that the parents tried to give answers they thought the researcher was looking for. They were advised to be honest and to provide answers according to their understanding and satisfaction.

\section{Findings and Discussions}

Table 1. Parents' Level of Education

\begin{tabular}{|c|c|c|c|c|}
\hline V7 & Frequency & Per cent & Cumulative Frequency & Cumulative Per cent \\
\hline 1 & 25 & 10.6 & 63 & 26.8 \\
\hline 2 & 57 & 24.3 & 120 & 51.1 \\
\hline 2 & 46 & 19.6 & 166 & 70.6 \\
\hline 4 & 52 & 22.1 & 218 & 92.8 \\
\hline 5 & 13 & 5.5 & 231 & 98.3 \\
\hline 6 & 4 & 1.7 & 235 & 100 \\
\hline
\end{tabular}


10.6 per cent of the parents had lower primary education; 24.3 per cent had higher primary education; 19.6 per cent had secondary education; 22.1 per cent had tertiary education and 5.5 per cent were graduates, while only 1.7 per cent was post-graduates.

Table 2. Responsibility

\begin{tabular}{|c|c|c|c|c|}
\hline V20 & Frequency & Per cent & Cumulative Frequency & Cumulative Per cent \\
\hline 1 & 59 & 25.4 & 59 & 25.4 \\
\hline 2 & 173 & 74.6 & 232 & 100 \\
\hline
\end{tabular}

25.4 per cent of the parents reported that they left the responsibility of the education of their children in the hands of teachers. At least 74.6 per cent did say that they provided adequate help that could promote the educational progress of their children by making available spare time to attend to children and helping with homework where necessary. They agreed that they should be more involved in making their children better citizens of tomorrow. This view is corroborated by Epstein (1992) who argued that learners at all levels do better academic work, have more positive school attitudes and other positive behaviours if they have parents who are aware, knowledgeable, encouraging and are involved. In addition, several studies conducted in different countries show that involving parents in instructional tasks has positive effects on learning (Campbell \& Mandel 1990; Coleman, 1998; Rosenholtz, 1989; Sanders \& Epstein, 1998).

The degree, to which parents involve themselves in their children's schooling by way of active participation and by showing an interest, is crucial to the successful outcome of education. Behr, Chevian, Mwamwenda, Ndeba and Ramphal (1988) emphasise that parents who provide a rich early environment are more likely to have children with adequate cognitive skills. Possession of these skills increases a child's self-esteem and leads to competence. Therefore, learners with intellectual disabilities also need such skills. Pelligrini (1988) declares that:

"Homes that are supportive before school tend to continue being supportive when children attend school. So, there is every chance of those already having an enriched experience getting richer while those with impoverished beginnings get poorer for many interacting reasons"

Most parents, as shown by data in table 1 possess very little academic skills which they can enrich their children's education. Children from such families will probably enter school lacking in the basics of general and self-expression. Most of the mothers were single mothers and housewives and were unemployed. Such families could be regarded as having a low socio-economic status and providing little opportunity for mental stimulation. Furthermore, there is also likely to be parental stress and parents may show less interest in encouraging their children to learn.

The community depends on the teacher as the secondary educator to ensure that young children will learn effective group behaviour and cultural patterns which are necessary if they are to adjust in life in a particular community. Teachers at school offer formal education to children with the aim of producing future adults who are physically strong, mentally alert, emotionally stable, culturally sound and socially efficient. Learners with intellectual disability also need to be offered such education by skilful teachers. Teachers are therefore expected to be well equipped with skills such as communication, imparting of knowledge and other related skills to help learners with intellectual disabilities to attain their objectives.

In this study, it was found that male teachers are far fewer in number than female teachers in special schools for learners with intellectual disabilities. Also a large number of teachers were found to be lacking the required skills to teach such children. Gradually, the shift to inclusive education is indeed occurring in South Africa. According to Ntombela (2011), under the tenets of the previous medical model, teachers were taught that learners with barriers to learning were best educated in separate classrooms and these beliefs can be difficult to change. Teachers consequently were trained to teach either general education or special education classes. Oswald (2007) emphasises that this has resulted in many South African teachers having little to no training or experience with learners who experience educational barriers.

In addition to exposure, many teachers feel they lack the training to adequately teach learners with intellectual disabilities. Some teachers express concern about their lack of knowledge of how to individualise programmes (Chhabra, Srivastava, and Srivastava (2010) while others express concern about the time, skills, resources and support necessary to meet the academic requirements of learners who experience barriers to learning (Scruggs \& Mastropieri, 1996). However, this study has found that there are still not enough support structures available yet to meet the needs of the learners with intellectual disabilities and that many teachers and parents are not well informed on how to apply the little knowledge or skills they have about learners with intellectual disabilities. 


\section{Conclusion and Recommendations}

The main aim of this study was to find out the role played by parents and teachers in the education of learners with intellectual disabilities, especially in black communities. Recognising individuals with disabilities as people first must be fully embedded in the education system and society in general. When these individuals are made to feel good about themselves, the stage is set for effective learning. A supportive environment where there is collaboration amongst teachers, parents, and community and learner support educators is key to success. This can be achieved by using strategies and practicing learning styles of choice, each reaching a level of achievement in accordance with his or her unique abilities. This affirms and confirms the need for educational support services to adopt a comprehensive and integrated approach to ensure that proper support is provided from various levels of the system. To achieve an inclusive school environment, a shift from a set of embedded assumptions and practices that encourage maintenance of the status quo to one that promotes reform is necessary (Engelbrecht, Oswald \& Forlin, 2006).

It is recommended that more should be done in educating teachers about parental involvement, and also educating and encouraging parents in participating in school activities. Parental involvement in the school programme would facilitate a continuity of the school programmes during school holidays. If parents are personally involved by volunteering they would be able to gain a better understanding of what intellectual disability is all about. Protective workshops for these learners should be developed for enhancing their chances of becoming independent citizens. Use simple, short and uncomplicated sentences to ensure maximum understanding. Individuals with intellectual disabilities should never be referred to as retarded. They should be allowed to do things for themselves when they want to and be used when helpful.

\section{References}

Angelides, P. 2008. Patterns of Inclusive Education through the Practice of Student Teachers. International Journal Inclusive Education, 12(3), 317-329.

Behr, A L.; Chevian, V L.; Mwamwenda, I S; Ndeba, E P. \& Ramphal, A. 1988. An Educational Psychology Journal of Intellectual and Developmental Disability Journal, 28(4), 369-379.for schools in Africa. Durban: Butterworths.

Campbell, J., Gilmore L., Cuskelly, M. 2003. Changing Student Teachers' Attitudes towards Disability and Inclusion. Journal of Intellectual and Developmental Disability, 28(4), 369-379.

Campbell, J \& Mandell A. 1990. Connecting Maths achievement to parent influence. Contemporary Educational Psychology, (15), 64-74.

Chhabra, S., Srivastava, R., \& Srivastava, I. 2010. Inclusive education in Botswana: The perceptions of school teachers. Journal of Disability Policy Studies, (20), 219-228.

Clark, M. \& Artiles, A. 2000. A Cross- National Study of Teachers' Attributional Patterns. The Journal of Special Education, 34(2), 77-89.

Coleman, P. 1998. Parent, student and teacher collaboration: The power of three. London: Sage.

Dixon, A. 1992. Parents: Full partners in the decision-making process. NASSP Bulletin, 76(543), 15-18.

Education White Paper 6. 2001. Special Needs Education: Building an Inclusive Education and Training System. Tripple CCC. Advertising and Research.

Engelbrecht, P., Oswald, M, \& Forlin, C. 2006. Promoting the implementation of inclusive education in primary schools in South Africa. British Journal of Special Education, (33), 121-129.

Epstein, J. 1992. School, Family and Community Partership; Caring for the Children We Share. Phi Delta-Kappan. 76:701-712

Forlin, C., Loreman, T., Sharma, U., Earle, C. 2007. Demographic Differences in Changing Pre-service Teachers' Attitudes, Sentiments and Concerns about Inclusive Education. International Journal of Inclusive Education, (1), 1-15.

Gray, D. E. 2004. Doing Research in the Real World. London: SAGE Publications.

Green, G. 1996. Early behavioural intervention for autism. In C. Maurice (Ed.). Behavioral Intervention for Young Children with Autism (pp.29-44). Austin, TX: Pro-Ed.

Hemmings, B., Woodcock, S. 2011. Pre-service teachers' views of inclusive education: A content analysis. Australian Journal of Special Education, 35(2), 103-116.

Henning, E., Van Rensburg, W. \& Smit, B. 2004. Finding Your Way in Qualitative Research. Pretoria: Van Schaik.

Loebenstein, H.2005. Support for learners with intellectual disabilities in the transition to secondary schools. Stellenbosch University.

Luftig, R.L. 1989. Assessment of learners with special needs. Boston: Allyn \& Bacon.

Nakken, H. \& Vlaskamp, C. 2002.Joining forces: supporting individuals with profound multiple learning disabilities. Tizard Learning Disability Review, (7) 10-16.

National Joint Committee on Learning Disabilities. (NJCLD). 1998. Operationalizing the NJCLD. Definition of Learning Disabilities for Ongoing Assessment in Schools. Asha, 40 (suppl. 18).

Ntombela, S. 2011. The progress of inclusive education in South Africa: Teachers' experiences in a selected district, KwaZulu Natal. Improving Schools 14(1) 5-14. doi: 10.1177/1365480210390082.

Oswald, M. 2007. Training teachers to become inclusive professionals. In: P. Engelbrecht \& L. Green (Eds). Responding to the challenges of inclusive education in Southern Africa (pp.140-158). Pretoria, South Africa: Van Schaik.

Palmer, D. 2006. Durability of Changes in Self-Efficacy of Pre-service Primary Teachers. International Journal of Science Education, 
28(6), 655-771.

Pawlyn, J. \& Carnaby, S. 2009. Profound Intellectual and Multiple Disabilities: Nursing Complex Needs. John Wiley \& Sons; Ltd Publication.

Pelligrini, A.D. 1988. Psychological bases for early education. Chichester: John Wiley.

Petry, K. \& Maes, B. 2007. Description of the support needs of people with profound multiple disabilities using the 2002 AAMR system: an overview of literature. Education and Training in developmental Disabilities (42), 130-143.

Rosenholtz, S.J. 1989. Teacher's workplace: The social organisation of schools. New York: Longman.

Sanders, M.G \&Epstein J. L. 1998. International perspectives on school, family and community partnerships. Childhood Education, (74): 340-342.

Schalock, R. L., Luckasson, R. A., Shogren, K.A. 2007. The remaining of mental retardation: Understanding the change to the term intellectual disability. Intellectual and Developmental Disabilities, (45): 116-124. Doi: 10.1352/19349556.

Schumacher, S. \& McMillan, J.H. 1997. Research in Education. A conceptual introduction. Longman. New York.

Scruggs, T. E., \& Mastropieri, M. A. 1996. Teacher perception of mainstreaming inclusion, 1958-1995: A research synthesis. Exceptional Children, (63), 59-74.

Vandergrift, J., \& Greene, A. 1992. Rethinking parent involvement. Educational Leadership, 50(1), 57-59.

Wanat, C. 1992. Meeting the needs of single-parent children: School and parent differ. NASSP Bulletin, 76(543), 43-48.

Winter, E. 2006.Initial Teacher Education: Preparing New Teachers for Inclusive Schools and Classrooms. Support for Learning, 21(2), 19-21.

Woolfson, L., Grant, E., Campbell, L. 2007. A Comparison of Special, General and Support Teachers' Controllability and Stability Attributions for Children's Difficulties in Learning. Educational Psychology, 27(2), 295-306.

The Arc. 2009. Introduction to Intellectual Disabilities. Available online at: http://www.thearc.org.aspx/ pid=2448. 